Shkodra Mimoza, Bislimi Arben. The impact of motor status on the quality children's life. Journal of Education, Health and Sport. 2021;11(6):101-108. eISSN 2391-8306. DOI http://dx.doi.org/10.12775/JEHS.2021.11.06.011

https://apcz.umk.pl/czasopisma/index.php/JEHS/article/view/JEHS.2021.11.06.011

https://zenodo.org/record/5016302

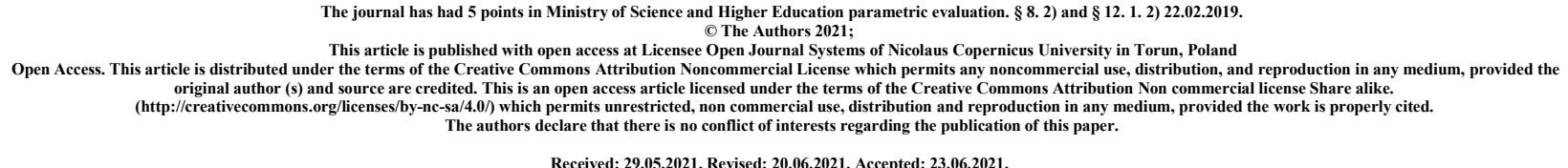

Received: 29.05.2021. Revised: 20.06.2021. Accepted: 23.06.2021.

\title{
THE IMPACT OF MOTOR STATUS ON THE QUALITY CHILDREN'S LIFE
}

\section{Mimoza Shkodra1, Arben Bislimi}

Mimoza Shkodra, PhD, Faculty of Physical Culture and Sports, AAB College, Email:mimoza.shkodra@aab-edu.net,

Arben Bislimi, Ma, Facultu of Physical Culture and Sports, AAB Collage, E- mail: arben.bislimi1@aab-edu.net

\begin{abstract}
The basic purpose of this paper is to distinguish between the motor characteristics of students (male-female) and 12-year-old age groups of SHFMU "Selami Hallaci" in Gjilan.

The sample of this research includes a total of 100 (50 female and 50 male) students who undergo regular physical education and sports two hours a week.

6 basic motor variables were applied in the research, and based on it, significant differences were obtained.

To confirm the differences between students in the basic motor variables, the T-test method was used. Based on the results obtained through this method, valid changes were realized in some of the basic motor variables of. Significant values were obtained in estimating the correlation in some of the motor variables.

All these important differences between the mean values in favor of men confirm and confirm that students (men) are more active and agile than the girls tested.
\end{abstract}

Key words: Pupils, students, basic motor, functional, differences. 


\section{Introduction}

It is not uncommon for information about children to grow in height and body mass to serve to understand their health status.

Physical activity plays an important role in a child's daily life. Their participation in physical activity is important for his / her relationships with peers both in terms of their physical and mental development.

The consequences of premature obesity are widespread throughout the world. Obesity can negatively affect children's current health, educational attainment, quality of life, and relationships with peers, etc. (WHO, 2016).

The whole figurative and physical tangle of the child is the basis of the formation of his personality. Recent research suggests that $75 \%$ of adults become ill as a result of illness when they were children, which means in every fourth child, so only $10 \%$ of those attending preschool are absolutely healthy.

A child with a high level of motor skills is much more physically active, and is accepted much more easily by their peers. They are also among the first to be accepted or selected for games or sortie school competitions, while a child who is left out of the opportunity to participate in these school competitions will always feel ignored (Kunz, 2009; Netelenbos, 2005).

Clumsy children are often children who sit and watch friends play, and this is a negative effect, not only on their motor skills, but directly affects the child's self-esteem, their mood, depression, anxiety, family relationships. and friends and also success in school. Nor should we forget that calorie intake is increasing and this tendency is not associated with physical activity so that these consumed calories are consumed but rather (Berkey et al., 2000; Boreham \& Riddoch, 2001; Epstein \& Goldfield, 1999 ).

\section{Methods}

According to the time orientation this is transversal research in which empirical and statistical methods will be applied and as a research technique is testing. Data collection was performed indoors (sports gym), in which children maintain a regular learning process. During the course of data collection, in addition to the author of the paper, five (5) professors of Physical Education were engaged who were previously trained for the data collection process.

The sample for this research consists of 12 year old students of the primary school "Selami Hallaqi" in Gjilan. The sample included 50 males and 50 females. Students are tested in the school sports hall.

During the selection of measuring instruments (tests) it was taken into account that they meet the basic metric characteristics, to suit the age and spatial conditions. The variables selected in this research hypothetically cover motor skills.

\section{The sample of variables}

MKVGJA - Long jump, MKVL- High jump, MVR20M- Running $20 \mathrm{~m}$.from the high start, MHTMK - Throwing the medical ball over the head, MHTM1D - Throwing the medical ball with one hand, MMSHMA- Contraction and extension of the abdominal muscles. 


\section{Statistical analysis}

The data are processed in such a way that first the central and distribution parameters are calculated for each variable and that: Minimum and maximum values (R.min-R.max), Arithmetic mean (Ma), Standard deviation (Ds) and Asymmetry parameters (SKEW and KURT). The Pearson correlation coefficient will be used to estimate the correlation of the variables.

Dis Discriminatory Analysis (t-test). The processing of the results will be done through the software SPSS version 23.

\section{Results and discussion}

Table 1 Presents the descriptive analysis of basic motor variables in the students of SHFMU "Selami Hallaci" in Gjilan.

Table 1. Basic statistical parameters of basic motor variables of 12-year-old students

\begin{tabular}{|l|r|r|r|r|r|r|r|}
\hline & \multicolumn{1}{|c|}{$\mathrm{N}$} & \multicolumn{1}{c|}{ Min } & \multicolumn{1}{c|}{ Max } & \multicolumn{1}{c|}{ Mean } & \multicolumn{1}{c|}{ DS } & \multicolumn{1}{l|}{ Skew } & \multicolumn{1}{c|}{ Kurt } \\
\hline MKVGJA & 50 & 1.00 & 1.85 & 1.398 & 0.217 & .150 & -.616 \\
\hline MKVL & 50 & 20.00 & 23.80 & 21.782 & 0.849 & .475 & .382 \\
\hline MVR20M & 50 & 3.50 & 5.20 & 4.375 & 0.343 & .336 & .108 \\
\hline MHTMK & 50 & 2.10 & 3.50 & 2.718 & 0.369 & .350 & -.560 \\
\hline MHTM1D & 50 & 2.60 & 5.10 & 3.512 & 0.580 & .909 & .060 \\
\hline MMSHMA & 50 & 9.00 & 26.00 & 18.697 & 4.112 & -.223 & -.296 \\
\hline
\end{tabular}

Normality of distribution of test results based on skeeness and kurtosis.

By analyzing the skeeness values, as well as by analyzing the parameters of the normal distribution of the results, it can be seen that the skeeness values in all basic motor variables are around zero and this tells us about the normal distribution of the results.

Analyzing the values of kurtosis, we can say that the distribution of the results of most anthropometric variables is not statistically different from the normal one.

From this we understand that the 12-year-old students of SHFMU "Selami Hallaci" in Gjilan are a sufficiently homogeneous group. 
Table 2. Basic statistical parameters of basic motor variables of 12-year-old students (male)

\begin{tabular}{|l|r|r|r|r|r|r|r|}
\hline & \multicolumn{1}{|c|}{$\mathrm{N}$} & \multicolumn{1}{c|}{ Min } & \multicolumn{1}{c|}{ Max } & \multicolumn{1}{l|}{ Mean } & \multicolumn{1}{c|}{ DS } & Skew & Kurt \\
\hline MKVGJA & 50 & 1.15 & 1.91 & 1.448 & 0.190 & .555 & .334 \\
\hline MKVL & 50 & 20.10 & 29.20 & 22.455 & 1.805 & 2.576 & 9.215 \\
\hline MVR20M & 50 & 3.72 & 5.12 & 4.410 & 0.380 & -.111 & -.655 \\
\hline MHTMK & 50 & 2.90 & 5.50 & 3.816 & 0.624 & .838 & .945 \\
\hline MHTM1D & 50 & 2.60 & 4.35 & 3.220 & 0.446 & .747 & .507 \\
\hline MMSHMA & 50 & 15.00 & 28.00 & 22.000 & 3.546 & -.176 & -.453 \\
\hline
\end{tabular}

Also in Table 2. The normality of the distribution of the tested results based on skeeness and kurtosis was assessed.

After evaluating the results we estimate that the skein values in most of the applied variables are around zero and this also shows us a normal distribution of the results.

Analyzing also the values of kurtosis, we can say that the distribution of the results of most anthropometric variables statistically does not differ from the normal one.

The highest value was obtained in the variable country high jump (MKVL), Skew $=2.576$, Kurt $=9.215$. where students (males) have not shown normal distribution of results, which has been observed in the research of other authors where explosive force tests often know to avoid the normal distribution of results always due to the sensitive age in which students are.

\section{Coefficients of correlations between motor variables in female students}

Table 3. Correlation coefficients of basic motor variables in female students

\begin{tabular}{|c|c|c|c|c|c|c|}
\hline & MKVGJA & MKVL & MVR20M & MHTMK & MHTM1D & MMSHMA \\
\hline MKVGJA & 1 & & & & & \\
\hline MKVL & .289 & 1 & & & & \\
\hline MVR20M & $-.386^{*}$ & -.085 & 1 & & & \\
\hline MHTMK & .295 & $.360^{*}$ & -.140 & 1 & & \\
\hline MHTM1D & $.357^{*}$ & .171 & -.081 & $.475^{* *}$ & 1 & \\
\hline MMSHMA & $.651^{* *}$ & .315 & $-.462^{* * *}$ & .190 & .332 & 1 \\
\hline
\end{tabular}

The correlation coefficients between the basic motor variables of the students (female) are presented in the table with number 5 . The sample of the tested is characterized by significant correlation between long jump (MKVGJA), running 20 meters (MVR20M), throwing the 
medical ball. one-handed (MHTM1D) and contraction and extension of the abdominal muscles (MMSHMA) where the correlation coefficients are relatively high (respectively $.386, .357, .651)$.

The variable jump from place to place (MKVL) has gained a correlation correlation with the variable throwing the medical ball over the head (respectively: .360).

The 20-meter sprint variable (MVR20M) has gained correlation correlation with the abdominal muscle contraction and extension variable (MVSS) respectively: -.462.

The medical ball throw variable overhead (MHTMK) has gained correlation correlation with the one-handed medical ball throw variable (MHTM1D) respectively: .475.

The variable throwing of the medical ball with one hand (MHTM1D) has gained correlation correlation with long jump (MKVGJ) and throwing of the medical ball over the head (MHTMK) respectively: $.357, .475$.

The abdominal strength muscle variable (MSWMA) has gained correlation correlation with the variable of long jump (MKVGJA) and running 20 meters (MVR20M).

Although applied tests are often used as standardized procedures for assessing speed, strength, and flexibility, etc., changes in their interrelationship indicate that these tests have certain specifics, and that the correlations of the results of these tests vary from low to low. mesme.

\section{Correlation coefficients between student variables (male)}

Table 4. Correlation coefficients of basic motor variables in students (males)

\begin{tabular}{|c|c|c|c|c|c|c|}
\hline & MKVGJA & MKVL & MVR20M & MHTMK & MHTM1D & MMSHMA \\
\hline MKVGJA & 1 & & & & & \\
\hline MKVL & -.176 & 1 & & & & \\
\hline MVR20M & $-.555^{\text {** }}$ & .328 & 1 & & & \\
\hline МHTMК & -.054 & .206 & .266 & 1 & & \\
\hline MHTM1D & .147 & $.536^{*}$ & .144 & .392 & 1 & \\
\hline MMSHMA & $.462^{*}$ & -.036 & $-.493^{*}$ & -.003 & .104 & 1 \\
\hline
\end{tabular}

Table 4 shows the correlation coefficients between the basic motor variables of students (males). The sample of test subjects is characterized by significant correlations between the variable Leap from place to length, running 20 meters and contraction and extension of the abdominal muscles (respectively: $-.555, .462$ ).

The variable applied jump from place to height has gained significant correlation with throwing the medical ball with one hand (respectively: .536).

The 20-meter running variable has gained significant correlation with the contraction and extension of the abdominal muscles (respectively: -493) which is natural.

It is inexplicable that the variable throwing the medical ball over the head did not gain statistically significant correlation with any of the other variables applied. 
Table 5. T-test among students in basic motor skills

\begin{tabular}{|c|c|c|c|c|c|c|c|c|c|}
\hline \multicolumn{10}{|c|}{ Independent Samples Test } \\
\hline & \multicolumn{2}{|c|}{$\begin{array}{l}\text { Levene's Test for } \\
\text { Equality of } \\
\text { Variances }\end{array}$} & \multicolumn{7}{|c|}{ t-test for Equality of Means } \\
\hline & \multirow[b]{2}{*}{$\mathrm{F}$} & \multirow[b]{2}{*}{ Sig. } & \multirow[b]{2}{*}{$\mathrm{t}$} & \multirow[b]{2}{*}{ df } & \multirow{2}{*}{$\begin{array}{l}\text { Sig. (2- } \\
\text { tailed) }\end{array}$} & \multirow{2}{*}{$\begin{array}{c}\text { Mean } \\
\text { Difference }\end{array}$} & \multirow{2}{*}{$\begin{array}{l}\text { Std. Error } \\
\text { Difference }\end{array}$} & \multicolumn{2}{|c|}{$\begin{array}{l}95 \% \text { Confidence } \\
\text { Interval of the } \\
\text { Difference }\end{array}$} \\
\hline & & & & & & & & Lower & Upper \\
\hline \multirow[t]{2}{*}{ MKVGJA } & .927 & .340 & -.881 & 98 & .382 & -.050 & .057 & -.164 & .064 \\
\hline & & & -.904 & 48.990 & .370 & -.050 & .055 & -.162 & .061 \\
\hline \multirow[t]{2}{*}{ MKVL } & 4.269 & .044 & -1.860 & 98 & .068 & -.673 & .362 & -1.398 & .053 \\
\hline & & & -1.632 & 27.264 & .114 & -.673 & .412 & -1.518 & .173 \\
\hline \multirow[t]{2}{*}{ MVR20M } & .893 & .349 & -.365 & 98 & .717 & -.036 & .098 & -.233 & .162 \\
\hline & & & -.357 & 41.887 & .723 & -.036 & .101 & -.239 & .167 \\
\hline \multirow[t]{2}{*}{ MHTMK } & 5.561 & .022 & -8.208 & 98 & .000 & -1.098 & .134 & -1.367 & -.830 \\
\hline & & & -7.438 & 30.851 & .000 & -1.098 & .148 & -1.400 & -.797 \\
\hline \multirow[t]{2}{*}{ MHTM1D } & .904 & .346 & 2.004 & 98 & .040 & .293 & .146 & .000 & .586 \\
\hline & & & 2.111 & 51.798 & .040 & .293 & .139 & .015 & .571 \\
\hline \multirow[t]{2}{*}{ MMSHMA } & .556 & .459 & -3.079 & 98 & .003 & -3.303 & 1.073 & -5.455 & -1.152 \\
\hline & & & -3.173 & 49.449 & .003 & -3.303 & 1.041 & -5.395 & -1.212 \\
\hline
\end{tabular}

Tables 5 show the values of the difference between the two arithmetic means, the value of the T-test, as well as the level of significance between female and male mothers in the treated basic motor parameters.

Based on the results obtained through this method, it can be concluded that from a total of six basic motor variables applied, significant statistical changes and significant values were realized in three variables of them included in the research and that: in the throw variable e medical ball on the head Sig $=.000$, throwing the medical ball with one hand Sig $=.050$ and contraction and stretching of the abdominal muscles $\mathrm{Sig}=.003$. Sig $=.002$ 
If we start from the arithmetic means we can say that in most of the basic motor variables the results obtained between the groups show that there are differences between the groups and that these differences are in favor of men which is understandable.

\section{Conclusion}

The system of applied basic motor variables, functional and quality of life (according to the liqueur test) have undergone basic statistical processing in this research where it is seen that although the difference between the minimum and maximum result in these variables, the results do not have any asymmetry pronounced by normal distribution.

The correlation coefficients of the basic motor variables, functional (body composition-daughter) and quality of life show that the obtained correlations are statistically significant among themselves in the level of reliability of $(p=0.01)$ and $(p=0.05)$ even that especially in the quality of life variables which have shown significant correlation at the 0.01 level of significance. In some of the basic motor variables applied and especially those of the explosive force of the arms and abdominal muscles significant differences have been gained in favor of men which is extremely clear that male strength alongside females is naturally acquired.

Schools, parents, local communities and society as a whole must ensure the conditions for healthy growth of children and young people, including healthy diets and regular physical activity.

\section{References}

Bailey, R. (2006). Physical education and sport in schools: A review of benefits and outcomes. Journal of School Health, 76(8), 397-401.

Berkey, C. S., Rockett, H. R., Gillman, M. W., \& Colditz, G. A. (2003). One-year changes in activity and in inactivity among 10- to 15-year-old boys and girls: Relationship to change in body mass index. Pediatrics, 111(4), 836-843.

Castelli, D. M., Hillman, C. H, Buck, S. M., \& Erwin, H. E. (2007), Physical fitness and academic achievement in third- and fifth-grade students. Journal of Sport \& Exercise Psychology, 29(2), 239-252.

Gopinath, B., Hardy, L., Baur, L.A., Burlutsky, G., \& Mitchell, P. (2012), Physical activity and sedentary behaviors and Health-Related Quality of Life in adolescents. Pediatrics, 130(1), 167-174.

Hardy, L. L., King, L., Farrell, L., Macniven, R., \& Howlett, S. (2010), Fundamental movement skills among Australian preschool children. Journal of Science and Medicine in Sport, 13(5), 503-508.

Hernandez, L. M., \& Blazer, D. G.(2006), Genes, Behavior, and the Social Enviroment- Moving Beyond the Nature/Nurture Debate. Washington, DC: The National Academic Press.

InBody User's Manual. (2009), Seoul, Korea: Biospace Co., Ltd. Ismail, A. H. (1967). The effect of a well-organized physical education program on a intellectual performance. Research in Physical Education, 1(2), 31-38. 
Jaakkola, T., \& Washington, T. (2013), The relationship between fundamental movement skills and self-reported physical activity during Finnish junior high school. Physical Education and Sport Pedagogy, 18(5), 492-505.

Jaakkola, T., Kalaja, S., Liukkonen, J., Jutila, A., Virtanen, P., \& Watt, A. (2009). Relations among physical activity patterns, lifestyle activities, and fundamental movement skills or Finnish students in grade 7. Perceptual and Motor Skills, 108(1), 97-111.

Janssen, I., Katzmarzyk, P. Boyce, W., Vereecken, C., Mulvihill, C., Roberts, C., . . Picket, W. (2005), Comparison of overweight and obesity prevalence in schoolaged youth from 34 countries and their relationships with physical activity and dietary patterns. Obesity Reviews 6(2), 123-132.

Myrtaj, N.,Shkodra, M. ( 2019). The impact of physical activities of aerobic type in body mass and volume parameters.Journal of Education, Health and Sport. 2019;9(9):50-57. eISSN 2391-8306

Shkodra, M., Myrtaj, N., Bislimi, A ( 2020). Effect of the quarterly training program on key morphological and functional parameters of females. Journal of Physical education and sport. DOI: $10.7752 /$ jeps.2020.02099

WHO ( World Health Organization). (2011), Waist circumference and waist-hip ratio: Report of a WHO expert consultation. Geneva, Switzerland:World Health Organization.http://apps.who.int/iris/bitstream/10665/44583/1/9789241501491_eng.pdf (accessed 11.10.2015.)

WHO ( World Health Organization). (2016), Report of the commission on ending childhood obesity. Geneva, Switzerland: WHO. http://apps.who.int/iris/bitstream/10665/204176/1/9789241510066 eng.pdf (accessed 15.04.2016.) 